\title{
TEXTOS MULTIMODAIS NA AULA DE INTERPRETAÇÃO TEXTUAL PARA SURDOS: UMA PROPOSTA DESAFIADORA E INCLUSIVA
}

Leidiani da Silva Reis é doutoranda em Letras na Universidade Estadual do Oeste do Paraná (UNIOESTE); é bolsista da Coordenação de Aperfeiçoamento de Pessoal de Nível Superior (Capes), com pesquisa voltada para a descrição da Língua Brasileira de Sinais (Libras). E-mail: leidianireis@ hotmail.com.

Iara Mikal Holland Olizaroski é mestranda em Letras na Universidade Estadual do Oeste do Paraná (UNIOESTE); especialista em Língua Portuguesa e em Educação Especial; graduada em Letras. Professora no Centro de Capacitação de Profissionais da Educação e de Atendimento às Pessoas com Surdez (CAS), da Secretaria Municipal de Educação de Cascavel-PR (SEMED) e na Rede Estadual de Ensino do Paraná (SEED). E-mail: iaramikal@hotmail.com

\begin{abstract}
Resumo
O presente artigo tem como objetivo refletir sobre o processo interpretativo de textos multimodais - notadamente charges - nas aulas de Português para surdos. Foi possível constatar, com base no estudo desenvolvido, um trabalho direcionado, efetivamente, para a construção de uma proposta inovadora de ensino de Língua Portuguesa para surdos, a qual aponta tanto os desafios quanto as possiblidades para uma educação mais inclusiva, em fase de implementação.
\end{abstract}

\begin{abstract}
Resumen
El presente artículo tiene como objetivo reflejar sobre el proceso interpretativo de textos multimodales - en especial las "charges" - en las clases de Portugués para sordos. Fue posible constatar, con base en el estudio desarrollado, un trabajo direccionado, efectivamente, para la construcción de una propuesta de enseñanza de Lengua Portuguesa para sordo innovadora, la cual apunta tanto los desafíos cuanto las posibilidades para una educación más inclusiva, en fase de implementación.
\end{abstract}

\section{Introdução}

Muito se tem discutido sobre a inclusão de alunos surdos nas instituições brasileiras de ensino, sendo que uma das questões mais desafiadoras para os educadores está diretamente relacionada ao ensino da Língua Portuguesa para esses indivíduos. Nessa perspectiva, tomando por referência os trabalhos desenvolvidos a partir do Projeto de Extensão "Língua Portuguesa para os surdos: o bilinguismo em evidência", em parceria com o Centro de Capacitação de Profissionais da Educação e de Atendimento às Pessoas com Surdez (CAS), o que aqui se propõe é uma reflexão referente ao processo interpretativo de textos multimodais - notadamente charges — nas aulas de Português para surdos.

Para tanto, pautamos a nossa discussão na abordagem sociointeracionista da linguagem, na qual o texto é visto como uma atividade interacional, criativa e social. Partindo-se desse princípio, a interpretação torna-se uma tarefa complexa que requer estratégias cognitivas e metacognitivas. Para efeito de sondagem, com base nas charges empregadas nas aulas ofertadas, constatamos que um dos requisitos fundamentais de construção de sentido do texto é o estabelecimento da intertextualidade, que, sem o devido acionamento de conhecimentos prévios, fragiliza a interpretação realizada pelo leitor. Não é possível ir além da superfície textual da charge sem o acionamento, por exemplo, do conhecimento de mundo do leitor.

Por ser composto pela linguagem verbal e não verbal, o gênero charge é considerado muito rico para ser trabalhado com alunos surdos. Considerando o caráter 
humorístico, informativo e opinativo das charges, bem como a ampla circulação social que assumem, o estudo da charge contribui para a formação de alunos surdos pensantes e ao mesmo tempo críticos, atributos esses cada vez mais solicitados pela sociedade. Com as análises feitas, observamos que tem sido possível desenvolver um trabalho direcionado efetivamente para a construção de uma proposta inovadora, a qual aponta tanto os desafios quanto as possiblidades para uma educação mais inclusiva, em fase de implementação. As iniciativas por nós realizadas mostram-se fundamentais para colaborar com a construção e a consolidação da Educação Bilíngue dos Surdos no Brasil.

\section{1) Uma breve contextualização sobre o ensino-aprendizagem do surdo}

O conhecimento referente aos métodos educacionais criados para os sujeitos surdos permite a compreensão da relação existente entre o comprometimento linguístico dessa comunidade, a qualidade das suas interações interpessoais e o seu desenvolvimento cognitivo. A história serve de suporte para que seja feita uma análise crítica das consequências de cada método de ensino no desenvolvimento desses indivíduos (POKER, 2002). Nesse contexto, é relevante destacar que, por longos anos, os surdos foram privados de se comunicarem em sua língua natural, visto que escolas, profissionais da saúde e familiares de surdos seguiam uma tradição de negação do uso de sinais, isso, a partir de 1880, quando no Congresso Internacional de Surdo-Mudez em Milão, na Itália, o método oral foi instituído na educação dos surdos. "Nesse congresso, a visão oralista defende que só por meio da fala o indivíduo surdo poderá ter seu desenvolvimento pleno e uma perfeita integração social" (SALLES, 2007, p. 55).

Essa decisão ocasionou imensurável perda para as línguas de sinais no mundo todo e um considerável atraso no desenvolvimento escolar dos alunos surdos. No caso do Brasil, essa situação só começou a mudar a partir de 2002 quando a Língua Brasileira de Sinais (Libras), língua natural utilizada pela comunidade surda brasileira, tornou-se obrigatória nas escolas de ensino regular, com a promulgação da Lei n ${ }^{\circ} 10.436$ de 24 de abril de 2002, regulamentada pelo Decreto $n^{\circ} 5.626$ de 22 de dezembro de 2005, o qual a reconheceu como segunda língua oficial do Brasil e em seu Cap. IV, Art. 14 postula que:

\footnotetext{
As instituições federais de ensino devem garantir, obrigatoriamente, às pessoas surdas acesso à comunicação, à informação e à educação nos processos seletivos, nas atividades e nos conteúdos curriculares desenvolvidos em todos os níveis, etapas e modalidades de educação, desde a educação infantil até à superior (BRASIL, 2005).
}

Desse modo, ficaria "resolvida" a questão do direito à educação escolar e, consequentemente, a inserção social desses indivíduos, pois, além de assegurar a garantia do ensino, tal decreto ainda prevê nesse mesmo artigo a obrigatoriedade, já na educação infantil, do ensino da Libras para alunos surdos e também da Língua Portuguesa, como L2:

Para o ingresso dos alunos surdos nas escolas comuns, a educação bilíngue - Língua Portuguesa/Libras desenvolve o ensino escolar na Língua Portuguesa e na língua de sinais, o ensino da Língua Portuguesa como segunda língua na modalidade escrita para 
alunos surdos, os serviços de tradutor/intérprete de Libras e Língua Portuguesa e o ensino da Libras para os demais alunos da escola. $\mathrm{O}$ atendimento educacional especializado para esses alunos é ofertado tanto na modalidade oral e escrita quanto na língua de sinais. Devido à diferença linguística, orienta-se que o aluno surdo esteja com outros surdos em turmas comuns na escola regular (BRASIL, 2002).

Tal inserção e garantia de ensino bilíngue - Libras/Língua Portuguesa - para surdos provocou nas escolas, tanto públicas quanto privadas, a obrigatoriedade de se adaptarem a essa nova realidade. Porém, o que se tem constatado é que há uma grande lacuna entre a ideal e a real escola de educação bilíngue. $O$ ideal bilinguismo seria aquele constituído não apenas no superficial uso de duas línguas no ambiente escolar, mas comprometido com o sistema linguístico de ambas as línguas. Diante disso, podese dizer que:

A promessa de uma abordagem bilíngue para educar os alunos surdos não foi plenamente realizada. Ou seja, foi parcialmente devido ao fato de que ela requer uma mudança de ver pessoas surdas como desativadas para vê-las como pertencentes a um grupo linguístico e cultural distinto, e em parte porque a educação bilíngüe com os alunos surdos difere de programas bilingues da língua falada, em várias maneiras (CHARLOTTE, 2006, p. 34, tradução nossa' ${ }^{1}$.

A abordagem educacional bilíngue da pessoa surda consiste na aquisição da Libras como língua natural e da Língua Portuguesa somente na modalidade escrita, como L2. Os bilinguistas defendem que o surdo deve estar em constante contato, desde a primeira infância, com pessoas fluentes em Libras - preferencialmente surdas - o que, na maioria dos casos, só ocorre mediante ao ingresso à escola. Quanto ao ensino da Língua Portuguesa, o objetivo principal é desenvolver no sujeito surdo a consciência da utilidade da escrita e da leitura, oferecendo-lhe uma metodologia de ensino própria, com sala de aula adequada, em que predomine o visual (QUADROS e SCHMIEDT, 2006). Nessa perspectiva, é notável a relevância da educação bilíngue para a aprendizagem desse indivíduo, sendo fundamental, para isso, que as atividades realizadas sejam adaptadas conforme suas necessidades.

Diante da complexidade com relação à leitura e interpretação de textos, ocorreunos ofertar um curso de Língua Portuguesa para Surdos - especificamente, interpretação textual - o qual pudesse atender às necessidades mais imediatas desses indivíduos. Pensando nesse público, partimos então para a preparação das aulas, produzidas com base na aplicação de metodologias específicas, dando origem a um trabalho de interpretação de textos multimodais, direcionado ao aluno surdo.

The promise of a bilingual approach to educating Deaf students has not been fully realized. This is partially
due to the fact that it requires a shift from viewing Deaf people as disabled to viewing them as belonging to 
a distinct linguistic and cultural group, and partly because bilingual education with Deaf students differs from spoken language bilingual programs in several ways (CHARLOTTE, 2006, p. 34).

\section{2) Processo de interpretação textual numa perspectiva multimodal: a charge em evidência}

O processo de interpretação requer estratégias específicas, as quais, segundo Menegassi (1995, p. 53), "são procedimentos conscientes ou inconscientes utilizados pelo leitor para decodificar, compreender e interpretar o texto". Kleiman (2009) caracteriza tais procedimentos como cognitivos e metacognitivos. As estratégias cognitivas, em especial, são essenciais no momento da leitura. Elas são caracterizadas como ações mentais inconscientes, que o leitor nem sempre é capaz de descrever:

As estratégias cognitivas regem os comportamentos automáticos, inconscientes do leitor, e o seu conjunto serve essencialmente para construir a coerência local do texto, isto é, aquelas relações coesivas que se estabelecem entre elementos sucessivos, sequenciais no texto (KLEIMAN, 2009, p. 50, grifo da autora).

Quanto às estratégias metacognitivas, Kleiman (2009) as refere como as operações sobre as quais o leitor tem domínio no ato da interpretação. A autora afirma que essa é "uma estratégia de controle e regulamento do próprio conhecimento" (KLEIMAN, 2009, p. 34).

Conforme os estudos de Kleiman, para que o leitor realize uma interpretação expressiva, se faz necessária a aplicação de duas estratégias, a cognitiva e a metacognitiva. Suas pesquisas baseiam-se "por um lado, na modelagem de estratégias metacognitivas, e, por outro, no desenvolvimento de habilidades verbais subjacentes aos automatismos das estratégias cognitivas" (KLEIMAN, 2009, p. 49).

Nessa perspectiva, Kleiman (2009) elenca alguns passos necessários ao ato de interpretar. Esse, a princípio, requer conhecimentos prévios, que são aqueles conhecimentos adquiridos durante a vida de cada indivíduo. São eles, segundo a autora, que "determinam as possíveis inferências realizadas com base em marcas formais do texto" (KLEIMAN, 2009, p. 26). Nessa linha de análise, a autora, na verdade, acaba por elencar três níveis de conhecimento que devem estar articulados pelo leitor durante o seu trabalho interpretativo, quais sejam:

O conhecimento linguístico, o conhecimento textual, o conhecimento de mundo devem ser ativados durante a leitura para poder chegar ao momento da compreensão, momento esse que passa desapercebido, em que as partes discretas se juntam para fazer um significado (KLEIMAN, 2009, p. 26).

O conhecimento linguístico a que se refere Kleiman (2009, p. 13) "abrange desde o conhecimento sobre como pronunciar português, passando pelo conhecimento de vocabulário e regras da língua, chegando até o conhecimento sobre o uso da língua". Tal conhecimento permite ao leitor identificar as palavras e perceber as relações estabelecidas entre elas, para, em seguida, poder ativar significados com base em seu conhecimento sintático, lexical e semântico. Sem o domínio do conhecimento linguístico, a compreensão do texto torna-se impossível. 
Quanto ao conhecimento textual, este se constitui no "conjunto de noções e conceitos sobre o texto" (KLEIMAN, 2009, p. 26). É esse o conjunto que vai permitir ao falante o reconhecimento dos diversos tipos de textos como pertencentes a cada gênero ou tipo textual. Por exemplo, se o leitor tem alguma proficiência em textos informativos, descritivos, argumentativos etc., ele já dispõe de uma estrutura formada a respeito desse tipo de texto, e a ativa quando se depara com textos dessa natureza. Quanto maior for seu conhecimento textual e seu contato com diferentes tipos de texto, mais facilmente chegará à compreensão (KLEIMAN, 2009).

Por fim, o conhecimento de mundo diz respeito aos conhecimentos já adquiridos e mentalizados durante a vida, abarcando "desde o conhecimento que um cientista tem sobre sua especialidade [...] até o conhecimento de que "é proibido fumar nos coletivos"” (FÁVERO, 2009, p. 73). Devemos ativá-los no momento da leitura, para assim compreendermos as informações do texto com mais habilidade.

É igualmente fundamental para o processo de interpretação que a leitura seja guiada por objetivo(s), pois isso "pressupõe reflexão e controle consciente sobre o próprio conhecimento, sobre o próprio fazer, sobre a própria capacidade. Opõe-se dessa maneira aos automatismos e mecanicismos típicos do passar o olho que muitas vezes é tido como leitura nas escolas" (KLEIMAN, 2009, p. 44-45). O leitor que vai ao texto com objetivos previamente definidos tem a capacidade de formular hipóteses a respeito do que será lido, ou seja, ele estará agindo e não se posicionando como um mero receptor de informações. Também, não menos importante, é necessário interagirmos com a leitura. Esse caráter interacional é que nos dará, no momento de uma interpretação, a capacidade de reconhecermos as intenções do autor por meio de pistas linguísticas.

Além desses mecanismos, devemos levar em consideração todas as marcas formais do texto, pois os sentidos serão mais bem captados se soubermos ler os implícitos, uma vez que estes podem ser recuperados por meio das imagens e dos elementos linguísticos. De acordo com Kleiman (2009), “o processo através do qual utilizamos elementos formais do texto para fazer as ligações necessárias à construção de um contexto é um processo inferencial de natureza inconsciente, sendo, então, considerado uma estratégia cognitiva” (KLEIMAN, 2009, p. 50, grifo da autora).

Segundo Kleiman (2009, p. 65), "o leitor constrói e não apenas recebe um significado global para o texto. Ele procura pistas formais, antecipa essas pistas, formula e reformula hipóteses, aceita ou rejeita conclusões". Assim sendo, a expectativa é que o leitor seja realmente capaz de transformar as informações presentes no texto em um novo conhecimento. Para tanto, faz-se necessário que ele aprenda a dominar as estratégias de interpretação, percebendo as marcas formais do texto e estabeleça relações entre as ideias nele apresentadas. Em outras palavras, é preciso que o leitor desenvolva habilidades que lhe permitam detectar as marcas que levarão às reais intenções do texto (BIDARRA; REIS, 2013).

O trabalho aqui realizado se volta, também, para um estudo relacionado às marcas formais do texto, sejam elas verbais ou não verbais - característica intrínseca do texto multimodal -, como componente eficaz no processo interpretativo. Nessa perspectiva, segundo Bidarra e Reis (2013), a partir do momento em que o leitor passa a valorizar e a 
analisar essas marcas, o trabalho de interpretação começa a fazer todo o sentido: é nesse instante que as intenções do autor são captadas.

$\mathrm{Na}$ charge — gênero abordado durante as aulas — , por exemplo, cada detalhe da imagem é carregado de significado e requer habilidades para captar os sentidos implícitos. Ferreira (2004, p. 451) define a charge como uma "representação pictórica, de caráter burlesco e caricatural, em que se satiriza um fato específico, em geral de caráter político e que é do conhecimento". Qualquer tentativa de interpretar uma charge vai requerer do leitor o estabelecimento de uma relação estrita entre a imagem, o escrito (se houver) e, é claro, o acontecimento atual. Nesta circustância, a linguagem não verbal é fundamental para a construção do significado textual, sendo ela carregada de implícitos a serem revelados no processo interpretativo.

Com base em Bakhtin (2003), lembramos que a charge é um gênero discursivo da esfera jornalística, organizado por elementos verbais e não verbais. Tal gênero tem como suporte de circulação principalmente jornais, embora apareça também em revistas, sites e outros meios. A charge tem por função primeira provocar o humor e o riso, recursos para atrair o leitor para algo mais sério, qual seja, a crítica que o chargista pretende fazer. Esse expediente torna-se bastante atraente e efetivo, alcançando rapidamente os objetivos de quem a produziu.

As charges, diferentemente dos outros tipos de linguagem, tornam-se especialmente interessantes no âmbito acadêmico por trabalharem sempre com notícias atualizadas e por adotarem um tom caricato, muitas vezes carregado de críticas, de leitura rápida, "engraçada" e, porque não, jovem. Seus conteúdos revelam não só os pontos de vista do chargista, como também suas intenções, buscas por adesões, pelas suposições levantadas e, ainda, pelas fortes orientações argumentativas contidas em sua constituição (BIDARRA; REIS, 2013).

\section{3) Contextualização do trabalho desenvolvido}

Ao considerar a perspectiva bilíngue da educação do surdo, desenvolvemos uma proposta diferenciada de ensino da Língua Portuguesa - especificamente, interpretação textual - voltada para uma metodologia visual dinâmica, preparando o sujeito surdo para as mais diversas situações sociais em que o português é requerido. Diante disso, o curso foi organizado com duração de 30 horas/aula, buscando, sobretudo, enfatizar a leitura e a interpretação textual.

Nesse contexto, disponibilizamos, portanto, aulas voltadas ao ensino de L2 a alunos surdos $^{2}$ que, embora tenham ensino superior, sentem algumas dificuldades em aspectos específicos da Intepretação Textual. Assim sendo, para o desenvolvimento de um trabalho eficiente, oferecemos apenas 10 vagas, pois, a nosso ver, essa quantidade é razoável para o acompanhamento e auxílio específico a cada um dos participantes. Como já mencionado, essa proposta se desenvolveu em parceria com CAS que, além de proporcionar um espaço físico, cuidou da divulgação e controle de frequência dos alunos, no caso seus professores surdos, instrutores da Libras para docentes da Rede Municipal de Ensino. 
Esses alunos surdos são professores do CAS, centro com o qual possuímos parceria por meio do Projeto de Extensão "Língua Portuguesa para os surdos: o bilinguismo em evidência".

O curso ofertado teve como objetivo desenvolver as habilidades linguísticas dos alunos surdos no que diz respeito à interpretação de textos escritos em Português, dos mais variados gêneros e temáticas. Nele, foram trabalhadas, entre outras, questões relacionadas à leitura e análise de textos relevantes, com vista ao desenvolvimento crítico e cognitivo do surdo, enquanto leitor.

Para as aulas, recorremos a recursos didáticos como multimídia, textos multimodais ${ }^{1}$, dicionários, softwares, atividades impressas e livros para leitura, conforme o conteúdo expresso no quadro 1.

\section{Quadro 1: Conteúdo programático referente ao curso ofertado}

\begin{tabular}{|l|c|}
\hline \multicolumn{2}{|c|}{ Leitura e Interpretação de Textos } \\
\hline 1. Estratégias de Leitura e Interpretação & $14 \mathrm{~h} / \mathrm{a}$ \\
1.1 Textos multimodais & \\
1.2 Palavras-chave do texto & \\
1.3 Intertextualidade; & \\
1.4 Conhecimento de mundo e leitura prévia & \\
1.5 Processos utilizados na produção de sentido do texto & \\
1.6 Decodificar, compreender e interpretar & $3 \mathrm{~h} / \mathrm{a}$ \\
\hline 2. Vozes sociais e ideológicas presentes no texto & $10 \mathrm{~h} / \mathrm{a}$ \\
\hline 3. Identificação das principais ideias do texto & \\
a. Seleção e hierarquização de ideias & \\
b. Construção de pressupostos & $3 \mathrm{~h} / \mathrm{a}$ \\
\hline 4. Identificação do processo de contexto e produção & \\
\hline
\end{tabular}

Fonte: Autores da Proposta (2016)

Com base no quadro apresentado, podemos dizer que o trabalho realizado nesse curso foi direcionado à formação de um leitor competente, com capacidade de interagir com o texto, de atribuir sentido ao que lê, considerando o contexto de enunciação envolvido no processo. Para ser bem sucedido na tarefa da leitura, interpretação e compreensão, mostramos aos alunos surdos que, face às várias possibilidades a seu dispor, ele deve selecionar aquelas que respondem às suas necessidades; para tanto, eles devem valer-se de estratégias adequadas a fim de alcançar os significados implícitos deixados pelo autor/artista (BIDARRA; REIS, 2013).

\footnotetext{
${ }^{1}$ Recorremos principalmente ao gênero charge, por considerar sua característica pictórica, dinâmica e interdisciplinar, acoplando-se à metodologia proposta (BIDDARA; REIS, 2013). 


\section{4) O trabalho com textos multimodais: alguns resultados}

Considerando que o principal objetivo do curso foi o desenvolvimento dos alunos face às "Estratégias de Leitura e Interpretação", os conteúdos trabalhados com eles abrangeram noções sobre textos multimodais, palavras-chave, intertextualidade, conhecimento de mundo, cujos textos lhes são passados previamente, como forma de familiarizar-se não apenas com a escrita, mas também em analogia à temática a ser tratada em sala de aula. Nesse curso, além desses tópicos, priorizou-se, paralelamente, a produção de sentido do texto, por meio da decodificação, da compreensão e da interpretação textual.

Com relação à intertextualidade, partiu-se da apresentação de textos multimodais os quais têm em comum o tema abordado. A título de ilustração, apresentamos no quadro 2 alguns textos exemplos que trabalhamos com os alunos.

\section{Quadro 2: Textos multimodais para leitura e interpretação}

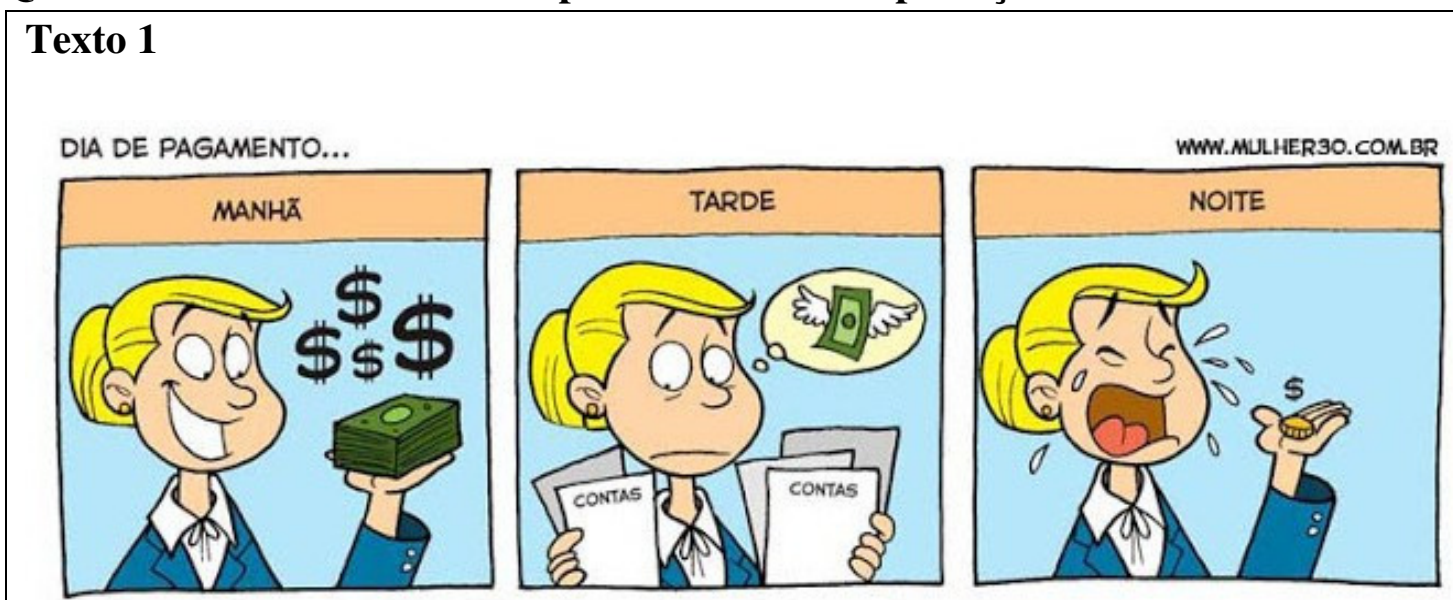

Fonte: $\underline{\text { http://mulher30.com.br/tirinhas/page/208 }}$

\section{Texto 2}
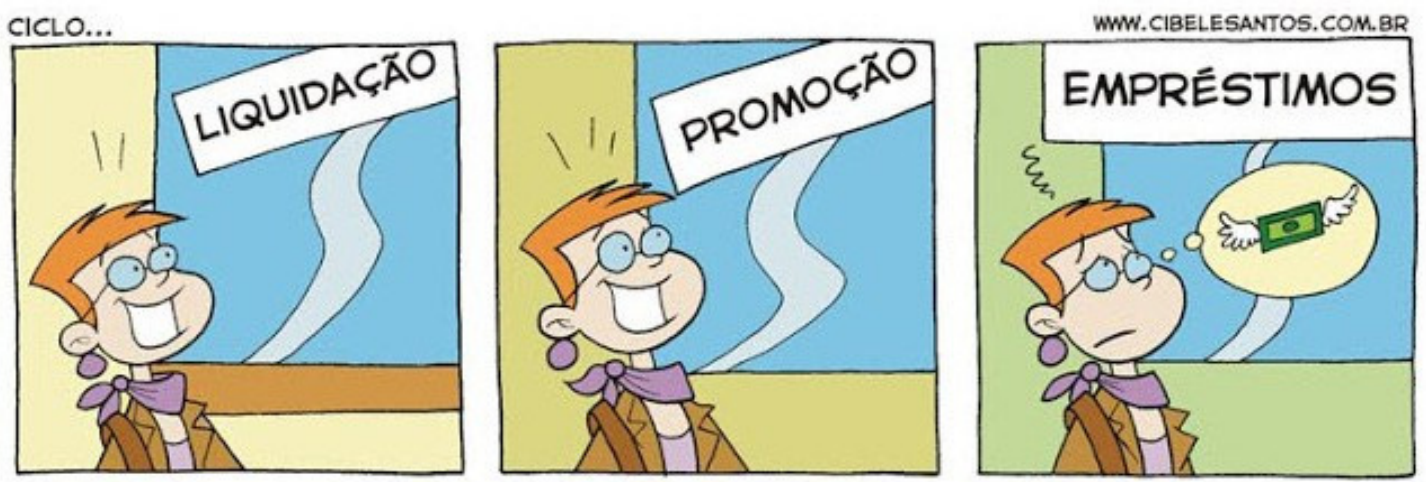

Fonte: http://mulher30.com.br/tirinhas/page/201

Após a apresentação dos textos, exploramos o conhecimento de mundo do surdo no que diz respeito ao tema "Educação Financeira", considerando desde a linguagem verbal até a não verbal. Vale ressaltar que, antes de apresentarmos as charges e as 
atividades a elas correspondentes, expomos uma breve contextualização histórica sobre salário mínimo, no que concerne a sua instituição por meio de lei bem como as necessidades que o mesmo deveria atender. Essa contextualização se deu por meio de textos coletados em mídias diversas (internet, jornais, livros, dentre outros), os quais adaptamos para atender apenas às informações necessárias. Durante a atividade, valemonos da exposição dos processos utilizados na produção de sentido do texto para, por fim, observar o nível de decodificação, compreensão e interpretação. Após discussões coletivas dos referidos textos, buscamos destacar os aspectos mais importantes, de modo a sedimentar o conhecimento adquirido durante as aulas sobre os temas abordados e já discutidos na turma.

Para alcançar os objetivos almejados, propomos aos alunos atividades que os fizeram refletir e interpretar cada texto multimodal solicitado, conforme apresentado em subtópico seguinte.

\title{
4.1) Algumas atividades de reflexão e interpretação textual aplicadas Quadro 3 -
} Atividade 1

\begin{tabular}{|l|}
\hline \multicolumn{1}{|c|}{ Educação Financeira - Conceito } \\
\hline Reflexão por meio de debates: \\
Quando e por que o salário mínimo foi instituído no Brasil? \\
Qual o valor do salário mínimo nacional e do salário mínimo regional do Paraná? \\
Com um salário mínimo nacional um pai de família com dois filhos consegue \\
garantir as despesas com alimentação, moradia, saúde, transporte, educação, \\
vestuário, higiene, lazer e previdência? \\
O que pode acontecer quando as despesas mensais ultrapassam ao valor do salário \\
recebido?
\end{tabular}

Promoções e/ou liquidações são benefícios ou armadilhas para as finanças?

Há recessão na economia brasileira?

Se sim, como você sente essa recessão?

Quadro 4 - Atividade 2

\author{
Título/Tema/Palavras-Chave
}


Dos textos acima identifique em cada um deles:

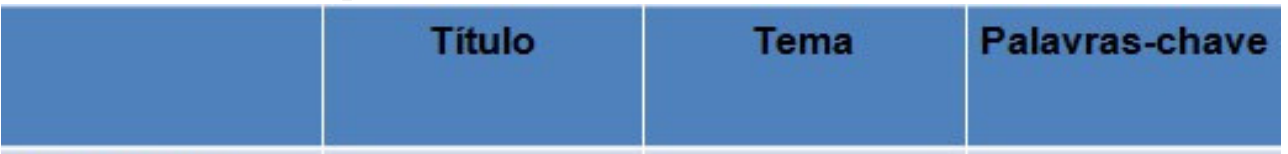

- Texto 1:

- Texto 2:

Quadro 5 - Atividade 3

\begin{tabular}{|l|}
\hline \multicolumn{1}{|c|}{ Construção de Pressupostos } \\
\hline Reflexão: \\
Título, tema e palavras-chave se relacionam? \\
Podemos presumir o assunto do qual trata cada texto por meio dessas \\
informações? \\
Ambos os textos tratam do mesmo assunto? \\
Se sim, qual o tema geral? \\
Se não, em que eles se diferenciam? \\
\hline
\end{tabular}

Quadro 6-Atividade 4

\section{Intertextualidade}


Os textos 1 e 2 dialogam entre si, pois tratam do mesmo assunto o qual está relacionado à Educação Financeira. Todos sabemos que o valor mensal que recebemos por nosso trabalho deve ser muito bem administrado para que possamos ter as finanças organizadas. Porém, como o salário mínimo hoje em dia não supre todas as necessidades, muitas vezes, ficamos com a "conta no vermelho" e isso pode trazer sérias consequências.

Observe o texto:

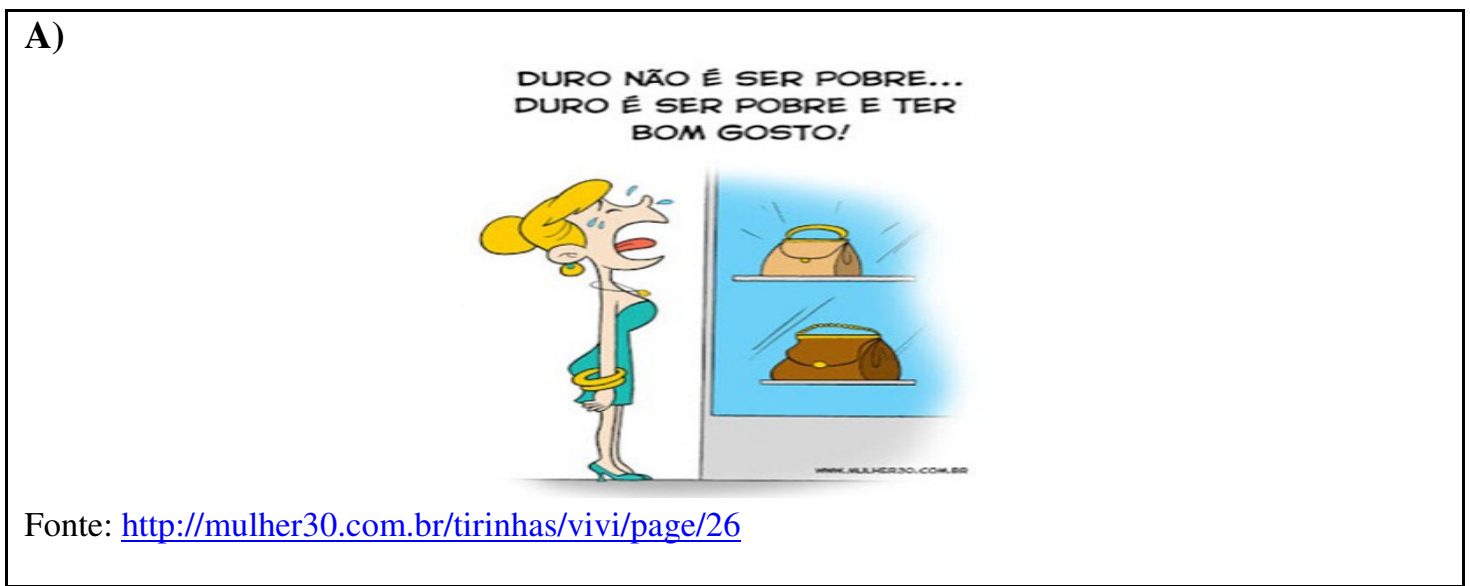

O texto aqui apresentado dialoga com os demais?

Se sim, em qual aspecto?

Se não, em que eles se diferenciam?

Observe mais duas charges: 


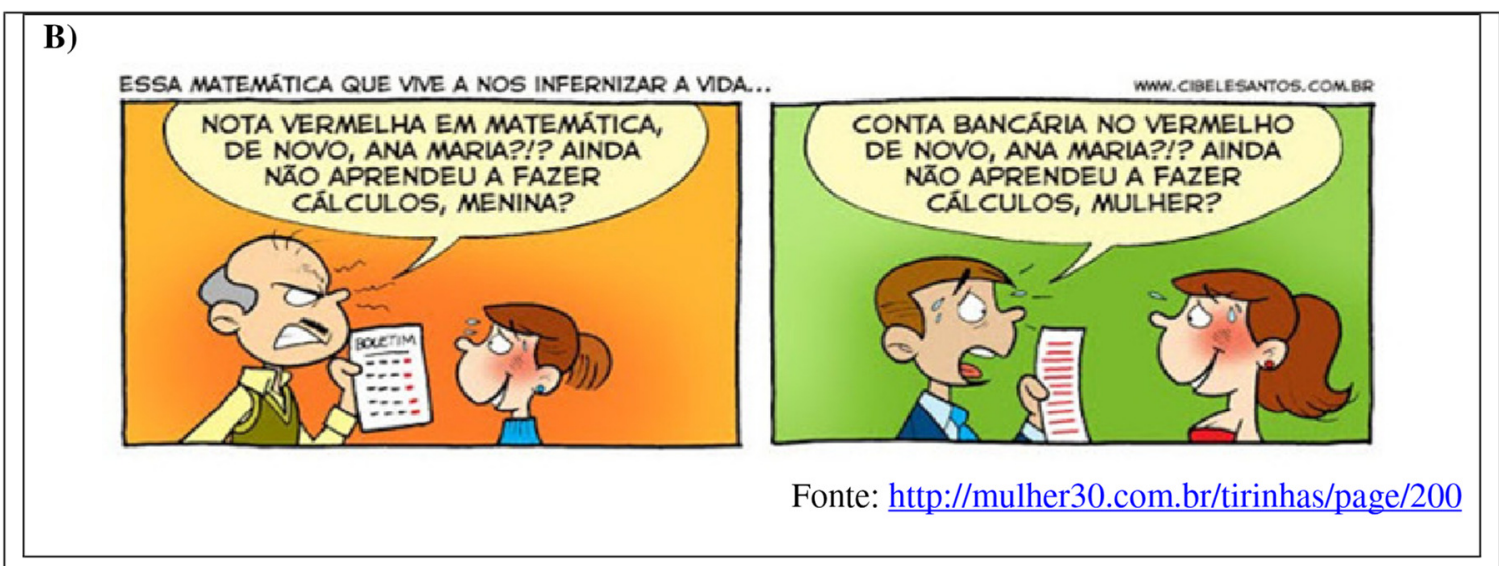

- O consumismo pode levar qualquer um a ficar com a "conta no vermelho". Com base nas tiras apresentadas, reflita e responda o que significa essa expressão:

- Identifique em cada um dos textos acima:

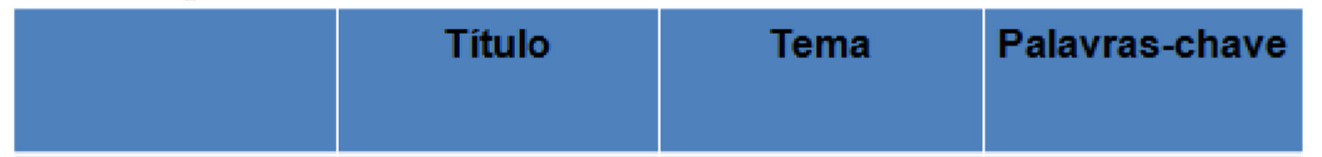

- Texto A:

- Texto B:

- Com base na identificação do título, tema e palavras-chave, responda:

- Os textos se inter-relacionam?

- Por quê?

Com essas atividades, observamos que para uma interpretação bem sucedida foi fundamental estabelecer intertextualidade com outros textos que trataram dos fatos aqui mencionados. Foi todo esse movimento que possibilitou compreender o significado das manifestações verbais e não verbais. Não seria possível ir além da superfície textual se não fossem acionados os conhecimentos prévios referentes ao assunto elencado nos textos. Entre tais conhecimentos, o de mundo, como se percebe, foi imprescindível para construção de inferências e, consequentemente, de significado textual (BIDARRA; REIS, 2013).

Esses conhecimentos (mundo, textual e linguístico) são fundamentais para que o aluno surdo consiga interagir com a charge em questão, iniciando, assim, a construção do significado da mesma. Neste sentido, segundo Kleiman (2009, p. 25), "este tipo de 
inferência, que se dá como decorrência do conhecimento de mundo e que é motivado pelos itens lexicais no texto é um processo inconsciente do leitor proficiente".

Nesse exercício interpretativo, também devemos levar em consideração todas as marcas formais do texto, como já mencionamos antes. Conforme Kleiman (2009), os sentidos serão mais bem captados se soubermos ler os implícitos, uma vez que estes podem ser recuperados tanto pela linguagem verbal, quanto pela não verbal. Em outras palavras, para ter uma interpretação textual bem sucedida, é necessário considerar que as charges vêm carregadas de significados, ou seja, cada detalhe que compõe a imagem, é essencial para a construção do significado do texto. Contudo, muito além disso, o objetivo da charge é, grosso modo, pelo riso, atrair o leitor para uma crítica política que é séria, feita, porém, de forma descontraída e mais leve que outros gêneros dentro da mesma esfera ou suporte (BIDARRA; REIS, 2013).

Quanto aos alunos surdos, pudemos perceber, ao longo do processo, que a compreensão do conteúdo foi efetivada por meio das estratégias diferenciadas aplicadas durante o curso as quais facilitaram não só a interpretação dos textos em questão, mas também a autonomia para o desenvolvimento das atividades propostas as quais puderam ser por eles realizadas com o mínimo de intervenção.

\section{Algumas considerações}

Quanto ao ensino da Língua Portuguesa - notadamente Intepretação Textual podemos dizer que não é algo trivial nem tampouco um processo fácil, independente do público para quem se leciona. Ainda, ensiná-la como L2 a sujeitos surdos torna-se mais complexo, considerando, principalmente, que são ambas - a Língua Portuguesa e a

Libras - de modalidade diferente, esta visuoespacial e aquela oroauditiva.

Constatamos, com base nas atividades propostas, que, para a interpretação da charge, é fundamental estabelecer intertextualidade com outros textos jornalísticos que trataram dos fatos aqui mencionados. Foi todo esse movimento que possibilitou compreender o significado das manifestações verbais e não verbais. Não seria possível ir além da superfície textual se não fossem acionados os conhecimentos prévios referentes ao assunto elencado na charge. Além disso, as marcas formais são essenciais para todo processo interpretativo de textos multimodais, devendo ser valorizadas no ensino de Língua Portuguesa direcionado ao sujeito surdo.

As aulas foram preparadas, portanto, no intuito de colaborar com a autonomia dos surdos diante dos textos mais diversos que lhes são apresentados. Nessa perspectiva, o uso de recursos visuais foi bastante explorado no decorrer do curso, visando maior compreensão da Língua Portuguesa, seguido de uma exploração contextual do conteúdo em estudo. Acreditamos que a proposta desenvolvida - embasada em textos multimodais - tem contribuído para a consolidação da Educação Bilíngue dos surdos no Brasil, somando aos trabalhos já existentes na área.

\section{Referências}

BAKHTIN, Mikhail. A estética da criação verbal. [Trad. Paulo Bezerra]. 4. ed. São Paulo: Martins Fontes, 2003. 
BIDARRA, Jorge; REIS, Leidiani da Silva. Gênero charge: construção de significados a partir de uma perspectiva interdisciplinar e dinâmica. Santa Cruz do Sul, v. 38, n. 64, p. 150- 168, jan./jun. 2013. Disponível em http://online.unisc.br/seer/index.php/signo Acesso em : 01 out 2013.

BRASIL. Decreto n ${ }^{\circ} 5.626$ de 22 de dezembro de 2005. Regulamenta a Lei no 10.436, de 24 de abril de 2002, que dispõe sobre a Língua Brasileira de Sinais - Libras e dá outras providências. Diário Oficial [da República Federativa do Brasil]. Disponível em: $<$ http://www.planalto.gov.br/ccivil_03/_ato2004-2006/2005/decreto/d5626.htm>.

Acesso em: 26 de ago. 2015.

Lei $\mathrm{n}^{\mathrm{o}} 10.436$ de 24 de abril de 2002. Dispõe sobre a Língua Brasileira de Sinais - Libras e dá outras providências. Diário Oficial [da República Federativa do Brasil]. Disponível em: <http://www.planalto.gov.br/ccivil_03/leis/2002/L10436.htm>. Acesso em: 26 de ago. 2015.BRASIL.

CHARLOTTE, Enns. A Language and Literacy Framework for Bilingual Deaf Education. Doctoral Thesis. Faculty of Education. University of Manitoba Winnipeg, MB R3T 2N2, Canada, 2006.

FERREIRA, Aurélio Buarque. Novo dicionário Aurélio da língua portuguesa. 3 ed. Curitiba: Positivo, 2004.

KLEIMAN, Ângela Bustus. Texto e leitor: aspectos cognitivos da leitura. São Paulo: Pontes, 2009.

MENEGASSI, Renilson José. Compreensão e Interpretação no processo de leitura: noções básicas ao professor. UNIMAR, Maringá, v. 17(I), p. 85-94, 1995.

POKER, Rosimar. Bortolini. Troca simbólica e desenvolvimento cognitivo em crianças surdas: uma proposta de intervenção educacional. Tese de Doutorado. UNESP - Marília, 2002.

QUADROS, Ronice Müller de; SCHMIEDT, Magali L. P.. Idéias para ensinar português para alunos surdos. Vol. 1. Brasília: MEC, SEESP, 2006.

SALLES, Heloisa Maria Moreira Lima et. al. (Orgs.). Ensino de língua portuguesa para surdos: caminhos para a prática pedagógica. Vol. 1. Brasília: MEC, SEESP, 2007. 